\title{
Some theoretical and methodological comments on the impact of policies on fertility
}

\begin{abstract}
Anne H. Gauthier*
Theoretically, and for reasons that I will shortly summarise in this presentation, there are strong reasons to expect policies to have a positive impact on fertility. Empirically, however, the evidence regarding the potential impact of policies of fertility is less clear cut. While numerous studies do indeed show a positive impact of policies, there is no consensus regarding the actual magnitude of the impact, nor about its short- or medium-term nature (Gauthier 2007). What I want to do in this presentation is consequently to reflect on the results from empirical studies by raising a number of theoretical and methodological issues.
\end{abstract}

\section{Theoretical model}

Let me first start with the theoretical model. Drawing from the economic theory of fertility, we expect parents to be rational actors and to be weighing the decision to have children against three elements: their preference for children (as opposed to other 'goods'), the cost of children, and an income constraint (Ermisch 2003). Policies in this model are therefore expected to have a positive impact on fertility through three possible channels (Gauthier 2007). First, they may have a positive impact on fertility by reducing the direct and indirect (opportunity) cost of children through various child care, education and health subsidies, as well as through cash benefits during maternity or parental leave. Second, policies may also have a positive impact on fertility by increasing household income, through direct cash transfers to families, such as child/family allowances, as well as indirect ones through the tax system. Finally, policies may also have an impact on the preference for children although this is something usually not considered in the literature.

In view of this model, it is therefore not surprising that most empirical studies find a positive impact of policies on fertility (see the review of the literature in Gauthier 2007). What is actually more surprising is the wide uncertainty regarding the actual magnitude of the impact and, as discussed below, the fact that most studies conclude that the impact of policies on fertility is actually quite small.

* Anne H. Gauthier, Department of Sociology, University of Calgary, 2500 University Drive NW, Calgary, Alberta T2N 1N4, Canada. Email: gauthier@ucalgary.ca 


\section{Theoretical and empirical issues}

So, what impact are we talking about? It is obviously difficult to come up with one single number since the estimates regarding the impact of policies on fertility vary widely across studies - a situation partly driven by methodological differences in the types of policies analysed and in the actual research design. Nonetheless, most studies estimate the impact of policies to be in the range of roughly 0.05 to 0.2 children per woman (see Gauthier 2007). In other words, the impact of policies on fertility tends to be relatively small and definitively much smaller than the perceived gap between ideal and actual fertility. ${ }^{1}$ I would like to suggest that there are five possible explanations for this small effect of policies on fertility.

First, the cash transfers to parents may be too small to make any real difference in the budget of households especially in view of the large cost of children. I do not have time here to delve into the estimation of the cost of children. But from various pieces of information, let us assume that the cost of two primary school age children to be about 15,000 US dollars per year for a middle-income family. ${ }^{2}$ In euros, and using the parity purchasing value for Italy, this is about $€ 13,000$ per year. ${ }^{3}$ Cash transfers to families vary greatly across countries, but in Italy they are about $€ 1600$ per year (for two children), so about 12 per cent of the actual direct cost of children. ${ }^{4}$ The cash payments during maternity and parental leave also vary greatly across countries, and moreover are usually subject to a maximum which greatly reduce their relative value for middle- and high-income families.

The second reason why we may not find a large impact of policies on fertility is that the cost of children is actually not the only element that matters for families. Take for example child care: of course the costs of it may matter to families but the availability of child care and its convenience, especially in terms of scheduling hours, may matter just as much. It is in fact worth noting that in most surveys, cash benefits are not necessarily the type of family policy that receives most support by respondents. Policies related to housing availability, child care availability, flexible hours of work, and part-time work are also often

\footnotetext{
While the gap between actual fertility level and fertility ideals is often used to assess the potential impact of policies, it is a measure that has been widely criticised in the literature (see Gauthier 2007).

2 The estimate is for the year 2006 and comes from Mark (2007). The study suggests that the cost of one child for a middle-income family is about $\$ 10,500$. If we assume the presence of economies of scale and further assume that the second child costs only 50 per cent of the first one, we obtain an estimate of about $\$ 15,000$ for two children.

3 Data from the OECD for 2006 (parity purchasing power index equal to .863).

4 This is the difference in the net income (disposable income) of a two-earner family with two children and the equivalent two-earner family without children. In both cases, one of the spouses is assumed to be earning 100 per cent of the average wage and the other 67 per cent. The data are for 2005 and were obtained using the online OECD tax-benefit calculator (see: http://www.oecd.org/document/18/0,3343,en_2649_34637_39717906_1_1_1_1,00.html).
} 
given (see for example results from the Population Acceptance Survey in Höhn, Avramov and Kotowska 2008).

The third reason may be related to what is actually happening inside the household in terms of gender division of domestic work. Several scholars have for example suggested that the reason for very low fertility in parts of southern Europe may be related to the gender inequity in households, especially the very low participation of men in household chores (Billari 2008; Romano and Bruzzese 2007). If this factor weighs heavily in couples' decision to have children or not, policies may consequently exert very little leverage (unless of course policies attempt to address the gender inequalities in the private sphere). ${ }^{5}$

The fourth reason is of a methodological nature, namely the fact that analyses often focus on the impact of a single policy on fertility, for example the impact of cash benefits on fertility, or the impact of the cost of child care. In reality what may matter for couples is not each policy on its own but the actual package of policies. Unfortunately we usually do not have the data to model the impact on fertility of such a package of policies. ${ }^{6}$

Finally, the fifth reason may be that empirical studies examining the impact of policies on fertility do so by analysing all individuals of childbearing age without taking into consideration the fact that a non-negligible proportion of individuals may not be in a position to have an additional child or a first child. Individuals may be experiencing illness or infecundity, they may not have a partner or may not be in a stable relationship, they may be experiencing marital problems or may disagree about having (other) children, they may be unemployed or fear that they may soon lose their jobs, etc. In other words, when modelling the impact of policies we usually do not consider the (so-called) population at risk of having a child. Now, it is true that we are interested in estimating the impact of policies on fertility for the overall population, but I would argue here that we would increase our understanding of the phenomenon if we were to first look at the impact of policies on the population at risk.

\section{Conclusion}

To conclude, what I am arguing here is that there are several reasons why we have not been able to observe a stronger impact of policies on fertility. In particular, I think that we need to work harder in understanding the actual theoretical mechanisms that lead to fertility decisions (including the role of non-financial constraints). We also need to devote a greater effort to improving the measurement of policies, especially the whole package of policies designed for

\footnotetext{
This is indirectly done in some countries by reserving part of the parental leave scheme to fathers (see Moss and O'Brien 2006).

6 To my knowledge, the best attempt at quantifying cash support for different types of families (from a cross-national perspective) is the work by Bradshaw (2007). However, it ignores support related to maternity and parental leave.
} 
families. And finally, we need to address the issue of heterogeneity in populations by identifying which subgroups make the most use of policies, and which subgroups may be most influenced by policies. Hopefully, some of these points will be taken up in future research.

\section{References}

Billari, F. 2008. "Lowest-low fertility in Europe: Exploring the causes and finding some surprises.” The Japanese Journal of Population 6(1); «http://www.ipss.go.jp/webj-ad/WebJournal.files/population/2008_4/01billari.pdf».

Bradshaw, J. 2007. "Child benefit packages in 22 countries.” In: H. Wintersberger et al. (eds.) Childhood, Generational Order and the Welfare State: Exploring children's social and economic welfare. Odense, University Press of Southern Denmark.

Ermisch, J. F. 2003. An Economic Analysis of the Family. Princeton University Press.

Gauthier, A. H. 2007. "The impact of family policies on fertility in industrialized countries: a review of the literature." Population Research and Policy Review 26: 323-346.

Höhn, C., D. Avramov, and I. E. Kotowska. (eds.) 2008. People, Population Change and Policies: Lessons from the Population Policy Acceptance Study. Vol. 1, Springer.

Mark, L. 2007. "Expenditures on Children by Families 2006." U.S. Department of Agriculture, Center for Nutrition Policy and Promotion." Miscellaneous Publication No. 1528-2006. «http://www.cnpp.usda.gov/Publications/CRC/crc2006.pdf».

Moss, P. and M. O'Brien (eds.) 2006. International Review of Leave Policies and Related Research 2006. UK: Department of Trade and Industry. «http://www.berr.gov.uk/files/file31948.pdf».

Romano, M. C. and D. Bruzzese. 2007. "Fathers' participation in the domestic activities of everyday life." Social Indicators Research 84: 97-116. 